\title{
3 The Role of the Input in the Acquisition of Code-Switching
}

\author{
Shannon Phillips and Margaret Deuchar
}

\section{Introduction}

This chapter will examine the little-studied question of how children acquire code-switching if they are brought up in a bilingual community where this is a common practice. We will focus on the relation between the input from the adult community of bilinguals and the child's (re)production of any code-switching patterns in the input. We define "code-switching" as the use of two or more languages in the same conversation and focus in this chapter on switching within an utterance. An excellent example from both adult and child speech is provided by Yip $(2013,134)$ from her study of a child acquiring Cantonese and English in Hong Kong. Example (1) is an utterance by an adult addressing a child:

(1) ngo5dei6 waan2-zo2 \# turtle sin1 laa1, hou2-mou2 aa3 we play-ASP turtle first SFP good-not-good SFP "Let's play with the turtle first, shall we?" (Yip 2013, 134)

In this example, the English noun turtle is inserted in an otherwise Cantonese utterance. In the reply by the child in Example (2), we can see that she mirrors the adult utterance by similarly inserting the English word turtle in an otherwise Cantonese utterance.

$\begin{array}{llllll}\text { (2) ngo5dei6 jau5 [/] jau5 } & \text { loeng5 } & \text { go3 turtle } & \text { gaa3 } \\ \text { we have have } & \text { two } & \text { CL } & \text { turtle } & \text { SFP } \\ \text { "We have two turtles!" } & \text { (Yip 2013, 134) } & \end{array}$

This general pattern of English insertions in Cantonese turns out to be common in the Cantonese/English bilingual community, and our chapter will address the question of how a child acquires the community switching patterns.

The data we shall analyse will be from another bilingual community, in Wales, UK. Although only about $20 \%$ of the population of Wales speak 
Welsh as well as English, bilingual speakers are concentrated in particular areas in the north and west of the country. We already know from data collected from adult bilingual speakers in these areas that they have a strong tendency to speak Welsh with each other and that about $10 \%$ of their speech involves intraclausal code-switching to English (see Deuchar, Webb-Davies, and Donnelly 2018, 90). Our research question asks how young developing bilinguals acquire these specific patterns and if they can be discerned in their earliest speech productions. Our analysis focuses on the data from six children in the CHILDES CIG1 corpus, a longitudinal study of Welsh/ English bilingual children between the ages of 1 and 3 (see Aldridge et al. 1998). We use the Matrix Language Frame (MLF; Myers-Scotton 2002) as a tool in comparing the structure of the mixed utterances (containing both Welsh and English) in the children's speech with that found in the adult community.

Attention to how linguistic input affects children's language acquisition was fairly sparse in many twentieth-century studies in which the Chomskyan assumption regarding the "poverty of the stimulus" (Chomsky 1980, 34) held sway. According to this assumption, the input played a relatively minor role compared with the language-specific mental predisposition that children were thought to bring to the language learning task. However, a few notable studies (e.g. Newport, Gleitman, and Gleitman 1977) did draw attention to the important role of parental input, and their insights were further built upon by the usage-based approach to language acquisition, which emerged towards the end of the twentieth century (cf. Langacker 1987; Behrens 2012). In the same period, there began to be increasing interest in the question of how children acquire more than one language, either from birth or in early childhood. Many case studies focusing on bilingual acquisition from birth appeared in the 1980s and 1990s (e.g. Hoffmann 1985; De Houwer 1990; Döpke 1992; Deuchar and Clark 1996; Köppe 1997). Because there were two languages in the input, attention was necessarily focused on who provided this input and in what quantity.

But most of these early bilingual acquisition case studies had two flaws from the perspective of the present study: they focused almost exclusively on parental input as opposed to input from the community, and in addition many of them explicitly or implicitly considered mixing or code-switching by parents to be undesirable and so did not study it in detail. The concern with mixing was that it might interfere with children's ability to separate the two languages being acquired. Thus there was often an unstated aim of ensuring that the children become as competent in their two languages as monolinguals in each language (see Grosjean's [1989] warning regarding this aim). This approach clearly ignores the possibility that code-switching may be a normal practice in the community and that these norms need to be acquired for children to become fully functioning members of the community. 


\section{Shannon Phillips and Margaret Deuchar}

\section{Code-Switching in Adults}

Over the past 40 years, code-switching has become one of the central topics of study for bilingualism research as people have realised that codeswitching is not an "isolated, quirky phenomenon but a widespread way of speaking" (Gardner-Chloros 2009, 9). Code-switching studies can act as a window into the nature and compatibility of the grammars of the world's languages. Chomsky's generative grammar emphasises the role of "competence" or I-language whereby language is the system that allows speakers to produce grammatical sentences (Chomsky 1986). Implied in this definition is the idea that each language forms a discrete system of rules. However, code-switching raises questions about how and when two systems are able to combine. Furthermore, code-switching offers insights into the processing constraints which lead people to prefer certain types of switches over others. Of particular interest within this field of structural code-switching research, and the type of code-switching considered here, is code-switching within individual clauses, otherwise known as "intraclausal" code-switching (cf. Deuchar 2012). Code-switching within the clause allows us to observe how the syntactic structures of the two languages interact.

The idea that code-switching can be governed by linguistic constraints emerged with the work of linguists such as Pfaff (1979) and Poplack (1980), both focusing on Spanish/English code-switching. Pfaff concluded that "Surface structures common to both languages are favoured for switches" (Pfaff 1979, 314), an important observation that is also reflected in Poplack's proposal of the "equivalence constraint" whereby speakers avoid code-switching constructions that violate the surface word order of either language involved in the mixed utterance (Poplack 1980, 581). Joshi (1985), studying Marathi/English code-switching, drew attention to the fact that code-switching between the two grammatical systems was governed by an asymmetric "switching rule" by which a speaker could switch from the language of the morpho-syntax within a clause (the Matrix Language) into the other language (the Embedded Language) but not vice versa (Joshi 1985, 192). Joshi's work formed the basis for the development of Myers-Scotton's (1993) Matrix Language Frame model. The components of the model are the "Matrix Language" (ML), which sets the morphosyntactic frame for mixed utterances, and the "Embedded Language" (EL), which provides the single lexemes and switched EL island constituents that are switched into the ML (Myers-Scotton 1993, 1). The main claim of the model is that "the ML sets the morphosyntactic frame for ML + EL constituents" (Myers-Scotton 1993, 7). The model specifies that the ML can be empirically verified on the basis of the two principles below (Myers-Scotton 1993, 83).

a. Morpheme Order Principle (MOP): in Matrix Language + Embedded Language constituents consisting of singly occurring Embedded 
Language lexemes and any number of Matrix Language morphemes, surface morpheme order (reflecting surface syntactic relations) will be that of the Matrix Language.

b. System Morpheme Principle (SMP): in Matrix Language + Embedded Language constituents, all system morphemes that have grammatical relations external to their head constituent (i.e. which participate in the sentence's thematic role grid) will come from the Matrix Language.

Myers-Scotton originally proposed the MLF on empirical grounds based on her study of Swahili/English speakers in Kenya (Myers-Scotton 1993), and the model has been successfully applied to many other language pairs (see, e.g. Carter et al. 2011; Hebblethwaite 2010; Ihemere 2016; Khan and Khalid 2018). These and other studies have shown us that asymmetry between the ML and EL is not only found within the clause but is also common across an entire corpus in that one of the two languages more frequently assumes the role of the ML. Hebblethwaite (2010) suggests that it is most often the lower status or minority language, which is most frequently the ML. Particularly relevant for the present study is the finding that in the Welsh/English bilingual community, the minority language Welsh is indeed the most frequent Matrix Language (cf. Deuchar, Webb-Davies, and Donnelly, 2018). However, few quantitative corpus-based studies have been done, although such studies are crucial to provide information regarding the input to children who are growing up in bilingual communities where codeswitching is common.

\section{Code-Switching in Children ${ }^{1}$}

Despite the fact that many of the early case studies of developing bilinguals did not study language mixing in detail, being more concerned with how children separated their two languages, there were a few studies that did focus on language mixing or switching in children. For example, Vihman (1985) noted that function words were more likely than content words to be mixed in early two-word utterances produced by a developing Estonian/English bilingual, and the same was reported by Deuchar (1999) in her study of Spanish/English bilingual acquisition (see also Deuchar and Vihman 2002, 2005).

Another approach was to consider whether code-switching in children appeared to be subject to the same constraints as adult code-switching, for example, testing the application of the MLF model outlined above to child speech. Paradis, Nicoladis, and Genesee (2000) took this approach to their bilingual child data, French/English data collected in Canada. They found that "the children obeyed all the constraints set out in the Matrix Language Frame model the majority of the time" (Paradis, Nicoladis, and Genesee 2000, 245). However, they did not relate the children's code-switching patterns directly to the input. Vihman (1998) tested the MLF model on 
Estonian/English data collected over four years in the USA from conversations between her two children, aged roughly 3-7 and 6-10 years, respectively. She found that the Matrix Language of utterances was either English or Estonian, but most frequently Estonian. She reported that "When we speak of CS [code-switching], then, we are essentially speaking of the use of English words and phrases within Estonian utterances" (Vihman 1998, 60). This preference for switching from Estonian to English rather than the reverse might have been due to English being the community language, but this possibility was not explored.

Other studies of bilingual development had also noted that some children's switching was more common from one of the languages to the other rather than the reverse. However, many investigators tended to ascribe such frequency differences in bilingual child speech to dominance or greater proficiency in one language than another, rather than to the greater frequency of one Matrix Language compared with another in the input. For example, Petersen (1988) proposed the "dominant-language hypothesis", according to which "in word-internal code-switching, grammatical morphemes of the dominant language may co-occur with lexical morphemes of either the dominant or the non-dominant language. However, grammatical morphemes of the non-dominant language may co-occur only with lexical morphemes of the non-dominant language" (Petersen 1988, 486). On the basis of the code-switching pattern in her data alone, Petersen concludes that the child's dominant language is English. A more rigorous test of the "dominant-language hypothesis" would require an independent measure of the child's language proficiency. Petersen does mention that the child (living in the USA) receives more input in English than in Danish, including from her peers, but takes this to support her assumptions regarding dominance rather than to consider the influence of input from the community. Lanza (1997a, 1997b) also finds frequency differences in the mixed utterances of two developing Norwegian-English bilinguals in Norway, Siri and Tomas. Siri exhibits more mixing than Tomas, but the mixed utterances of both generally show a Norwegian grammatical frame with English insertions. Lanza interprets this pattern as exhibiting their dominance in Norwegian in line with Petersen (1988). However, she also notes that Siri's data can be accounted for in terms of the Matrix Language Frame model (MyersScotton 2002) and that Norwegian can thus be described as the Matrix Language of Siri's mixed utterances.

What neither Petersen nor Lanza appears to consider is the potential role of the community in providing input in which one Matrix Language is more frequent than the other. The child in Petersen's study was living in the USA, where English can be assumed to be the majority language. In Lanza's study the children lived in Norway, where the insertion of English items into a Norwegian grammatical frame is a frequently attested pattern in adults (cf. Grimstad, Lohndal, and Åfarli 2014). Few studies have separated the role of dominance and of the community language in bilingual acquisition. An 
exception, however, is Patuto et al. (2014), who found that the community language had a greater influence on code-switching than individual dominance, measured by comparing the MLU (mean length of utterance) in the two languages.

Despite the lack of emphasis in research work on the role of the community language, there has been some attention to the role of the input by parents in the development of code-switching in children. An early pioneer in this area was Goodz (1989). She used recordings of both adult and child speech to investigate quantitatively the relation between parental mixing in the input and mixing in the children's productions. Goodz found positive correlations between the child's and the mother's code-mixing in three out of the four children, but only in one of the child's mixing in relation to the father's. More recently, Baker and Van den Bogaerde (2008) investigated the extent to which the combination of Netherlands Sign Language (NGT) and Dutch used by deaf parents when addressing their deaf children was used in the child productions. They found that when the parents used utterances that included both signs and spoken or mouthed words, NGT was most commonly the "base language" of such utterances, and this pattern was replicated in the deaf children's productions.

One of the first studies to shift attention away from parental input to that of non-parental interlocutors, was that by Comeau, Genesee, and LaPaquette (2003). They were able to demonstrate that French/English developing bilinguals in Canada varied their rates of mixing to reflect that of their interlocutors to a greater extent than that of their parents. One problem that arises in comparing the results of studies of this kind is that not all studies use the same definition of language mixing. Many studies share the practice of identifying utterances containing words from more than one language as mixed, but some also consider utterances to be mixed if they are in the non-designated language, i.e. not in the main language the adult is using to address the child. This problem is illustrated in the study by Yip and Matthews (2016) of children acquiring Cantonese and English in Hong Kong. In this study, they note that the children mostly follow the pattern common in the adult community of inserting English items into a Cantonese morphosyntactic frame (as in Example (2) above) rather than following the much rarer pattern of inserting Cantonese items into an English morphosyntactic frame. But if a child were to produce an utterance like Example (2) in a recording where the adult was speaking English, the utterance would have been coded by Yip and Matthews as involving mixing in an English context, despite the fact that it does not have an English morphosyntactic frame.

This problem could have been avoided by coding utterances as either unilingual or mixed and, if mixed, as having Matrix Language A or B. Such an approach was taken by Eichler, Hager, and Müller (2012) in their study of 16 developing bilinguals who were acquiring either German and a Romance language or two Romance languages. One child, Marie, was acquiring 
German and French in France and was recorded in both German and French "contexts", with the language of the context being that used by the adults. In a recording in which Marie was being addressed in German, she produced the utterance "c'est fini le bett" ("the bed is made") in which the German word Bett 'bed' has been inserted in a French morphosyntactic frame. If the "mixed" portion were identified as that in the non-designated language, then it would be c'est fini le, the French part of the utterance, although mixing of non-constituents in this way would be unusual. An alternative was to identify the utterance as having a French Matrix Language with a German insertion. In an analysis of mixed DPs (Determiner Phrases) like le bett, produced by the children, the investigators discovered that the determiner almost always matched the language of the verb, a common pattern in adult speech not widely recognised at the time of their study, but demonstrated later by Blokzijl, Deuchar, and Parafita Couto (2017). The approach by Eichler, Hager, and Müller (2012) paved the way for a recognition, pursued in the present study, that developing bilinguals, like adults, may combine languages in ways similar to the adults in their community, and that identification of mixing or switching should be based on syntactic criteria rather than on the language choice of the adult in the same conversation.

\section{The Present Study}

\subsection{Research Question}

Given the lack of attention in previous work to the way in which code-switching patterns in the adult community provide input to the acquisition of bilingual code-switching in children, our study makes use of both adult and child corpora from the same bilingual community in order to determine the extent to which the adult norms appear to be replicated in child speech. In particular, we shall be focusing on whether Welsh turns out to be the most frequent Matrix Language in child code-switching as well as adult code-switching.

\subsection{Data}

The corpus of adult data (known as Siarad, the Welsh word for "speak") was collected between 2005 and 2008 from 151 bilingual Welsh-English speakers in Wales, with the speakers being predominantly based in the north. It consists of 447,507 words in 40 hours of conversations between pairs or groups of speakers who were known to one another and is available publicly on the website bangortalk.org.uk and talkbank.org. Here can be found transcripts of the recordings in CHAT format (see MacWhinney 1991), including glosses and translations of the utterances into English. The recordings are also available. Further details regarding the method of data collection and the profile of the speakers are available in Deuchar, WebbDavies, and Donnelly (2018). 
The corpus of child data is known as the Welsh Acquisition Database (or CIG1) and was collected in 1996-1997 as part of a longitudinal study of children aged 18-30 months who were acquiring Welsh in the bilingual communities of north-west and mid-Wales (see Aldridge et al. 1998). General information about the corpus is available at https://childes.talk bank.org/access/Celtic/Welsh/CIG1.html. Here the investigators state that "All the parents (apart from one who learned Welsh from 3;0) were firstlanguage speakers of Welsh". We know that the parents all spoke English as well because virtually everyone in Wales knows English (cf. Gathercole and Thomas 2009) and because the transcripts show frequent code-switching into English by the adults. The data consists of 304,846 words in 84 hours of conversations recorded between seven individual child speakers and the researchers and/or family members. The children's pseudonyms and their ages during the study are listed in Table 3.1.

The two corpora were collected within about ten years of each other, meaning that we can consider the speech of adults in the two corpora to be comparable. About half of the speakers in the adult corpus were over 40 years old between 2005 and 2008, so we can assume their language patterns to be similar to those in the community providing input in the 1990s. Furthermore, the adults and children in both corpora were recorded in overlapping geographical areas.

Although we were able to use the analysis of code-switching in the Siarad corpus of adult speech conducted by Deuchar, Webb-Davies, and Donnelly (2018), we decided also to analyse the actual adult input to one of the children, Dewi, as represented by the recordings of his speech in interactions with adults. Our focus, as in the analysis of the child speech, was the distribution of the ML in mixed utterances. There were four adult speakers who addressed Dewi in the recordings of his speech: Mam - Dewi's mother, Dad - Dewi's father, and Susan and Alice - the investigators. In the recordings at least one investigator was present, and in the majority of the cases the investigator was alone with the child. ${ }^{2}$ All of the adult speakers were bilingual in Welsh and English. The scope of our study did not allow a detailed analysis of all the adult speech in the CIG1 corpus, but the speech sample provided by Dewi's interlocutors provides a sample of actual input

Table 3.1 CIG1 Child Speakers and Ages

\begin{tabular}{ll}
\hline Child pseudonym & Age \\
\hline Alaw & $1 ; 1.19-2 ; 3.21$ \\
Dewi & $1 ; 9.21-2 ; 6.9$ \\
Rhys & $1 ; 8.30-2 ; 5.21$ \\
Elin & $1 ; 5.8-1 ; 9.20$ \\
Bethan & $1 ; 7.28-2 ; 4.20$ \\
Melisa & $1 ; 6.20-2 ; 3.17$ \\
Rhian & $1 ; 6.17-2 ; 3.23$ \\
\hline
\end{tabular}


to a child which, like the data from Siarad could be compared with the speech of the children in CIG1.

\subsection{Method of Analysis of Adult Corpus Siarad (Deuchar, Webb-Davies, and Donnelly 2018)}

In order to identify the patterns of code-switching in the Siarad data, all clauses with finite verbs were extracted from the transcripts (available at bangortalk.org.uk). Each word in the transcripts had been coded as Welsh or English according to whether the word was (1) only to be found in a Welsh dictionary and therefore coded Welsh; (2) only to be found in an English dictionary and therefore coded English; and (3) to be found in both language dictionaries and therefore coded as ambiguous between Welsh and English. ${ }^{3}$ The clauses were coded for two types of information: (1) whether they were mixed or unilingual and (2) whether the Matrix Language was Welsh or English. Clauses containing words from both Welsh and English were coded as mixed, whereas clauses containing words from only one language were coded as either unilingual Welsh or unilingual English. The Matrix Language was identified according to the language of the finite verb, either Welsh or English. This was an operationalisation of the System Morpheme Principle, outlined above in Section 2. The Morpheme Order Principle was also relevant, but the System Morpheme Principle was prioritised as it turned out to be simpler to implement using automatic analysis. The method of automatic analysis is described by Deuchar, Webb-Davies, and Donnelly (2018, 86-92). The method allowed the authors to deal with a total of 66,428 clauses, both unilingual and mixed and to arrive at a quantitative overview of the distribution of types of clauses and their Matrix Language in the entire corpus of data. This distribution gives us an idea of the relative frequency of the various types of clauses and thus their patterns in the input to children acquiring Welsh and English.

\subsection{Method of Analysis of Child Data in CIG1 Corpus}

\subsubsection{Extracting the Data from the CIG1 Corpus}

In order to directly compare the mixing patterns in the children's speech with the mixing patterns in the adult speech reported by Deuchar, WebbDavies, and Donnelly (2018) we focused only on the mixed utterances in the CIG1 dataset.

A mixed-language utterance was defined as an utterance containing both English and Welsh words, so was always longer than one word. For three of the speakers (Bethan, Melisa, and Rhian) the mixed utterances were extracted manually. For the other child speakers (Alaw, Dewi, Elin, and Rhys), the English language tags (“@s:eng”, “@s”, “xs”, “xxs” in the transcripts) provided by the project researchers in these transcripts were only 
used to automatically extract any utterances with English material using the CLAN programme (MacWhinney 1991). Any of the extracted utterances that included only English material were then excluded from our mixed utterance dataset. For instance, utterances like Example (3) were classified as mixed and were thus included in our dataset for analysis while utterances like Example (4) were classified as English only and thus were not relevant for an analysis of code-switching.

(3) mae

o 'n mynd

i $\operatorname{crash}^{5}$

[Rhys020521 - Rhys]

be.V.3S.PRES PRON.3S.M PRT go.NONFIN to crash.NONFIN

"it is going to crash" 6

(4) swimming costume

[Melisa011106 - Melisa]

"swimming costume"

As part of our criteria for labelling an utterance as mixed, we specified that any English material (e.g. "toys" in Example (3)) had to be searched for in the Welsh dictionary ${ }^{7}$ in case it existed as a Welsh word, albeit borrowed from English. Lipstick in Example (5) below is a good example of an English word that has been borrowed into Welsh and appears in the Welsh dictionary as lipstic "lipstick". The English word lipstick and the Welsh word lipstic are phonologically similar, meaning that a given utterance of either word could not be marked confidently as either Welsh or English, and would be classified as linguistically ambiguous as explained in Section 4.3. Other linguistically ambiguous words included bello (Welsh belo), yeah (Welsh ie ), cement (Welsh sment), jeans (Welsh jîns), and yoghurt (Welsh iogwrt). Okay and come on were also treated as linguistically ambiguous as were commercial and proper names as in Examples (6) and (7) below.

(5) lipstick fi

[Alaw020212a - Alaw]

lipstick my.PRON.1S

"my lipstick"

(6) LCB yn mynd

[Rhys011108 - Rhys]

JCB PRT go.V

"JCB (excavator) go"

(7) mixer Dewi

[Dewi011018 - Dewi]

mixer Dewi

“Dewi's mixer”

Utterances like those in Examples (5)-(7), which did not contain at least two linguistically unambiguous words from both languages, were excluded 
from the dataset for analysis. In addition, potentially mixed utterances were excluded where the transcription indicated uncertainty about the utterance. See Examples (8) and (9) below. ${ }^{8}$

$$
\begin{aligned}
& \text { (8) < fish sy 'ma> [?] } \\
& \text { fish is this } \\
& \text { "this is a fish" } \\
& \text { (9) <xxx> [=? mae] doli xxx [=? yn] cheeky [Alaw020004 - Alaw] } \\
& \text { be.V.3S.PRES dolly PRT cheeky } \\
& \text { "the dolly is cheeky". }
\end{aligned}
$$

Despite the necessity for excluding various utterances from our dataset of mixed utterances, we still had a total ${ }^{9}$ of 300 mixed utterances to analyse, as outlined in Table 3.2.

\subsubsection{Method of Coding the Child Data}

All of the mixed-language utterances were coded for Matrix Language (Welsh or English). The Matrix Language was identified by applying the MOP and the SMP. This section outlines the specific points of contrast between Welsh and English grammar, which were used to determine the ML for the child CIG1 utterances, first for the MOP and then for the SMP.

The MOP could be applied to the CIG1 data to determine the ML when there was a divergence between the word order of Welsh and English, as in the example below of a modified noun phrase. Within noun phrases in English, the typical word order has a modifier, such as an adjective preceding the noun (10).

$$
\begin{aligned}
& \text { tough day } \\
& \text { "tough day" }
\end{aligned}
$$

Table 3.2 Child Mixed Utterances in CIG1

\begin{tabular}{lc}
\hline Speaker & Total Mixed Utterances \\
\hline Alaw & 60 \\
Dewi & 81 \\
Rhys & 118 \\
Elin & 14 \\
Bethan & 3 \\
Melisa & 13 \\
Rhian & 11 \\
Total: & 300 \\
\hline
\end{tabular}


Within noun phrases in Welsh, the typical word order is where the noun precedes a modifier such as an adjective, as shown in Example (11).

$$
\begin{aligned}
& \text { dynes hyll } \\
& \text { woman old.ADJ } \\
& \text { "an old woman" }
\end{aligned}
$$

[Alaw020317 - Alaw]

Because of the divergence in word order between English and Welsh, the order of the noun and the adjective in a noun phrase can be used to indicate the ML in mixed utterances using the MOP alone. This method is illustrated in the CIG1 data in Examples (12) and (13). The noun + adjective word order in (12) identifies the noun phrase as having a Welsh ML while in (13) the adjective + noun order indicates an English ML.

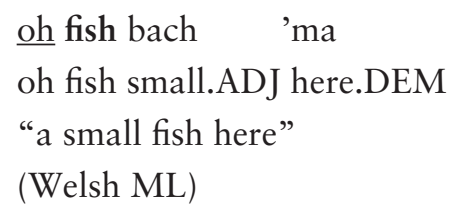

$$
\begin{aligned}
& \text { mawr fish } \\
& \text { big.ADJ fish } \\
& \text { “a big fish” } \\
& \text { (English ML) }
\end{aligned}
$$

[Dewi020523 - Dewi]

As previously outlined above, the SMP indicates that all system morphemes with grammatical relations external to their head constituent (including subject-verb agreement) will come from the Matrix Language. To identify the ML using the SMP in our mixed utterance dataset, we looked for the language of the subject-verb agreement. For instance, Example (14) has agreement between the singular third-person verb mae and the pronominal subject $O$.

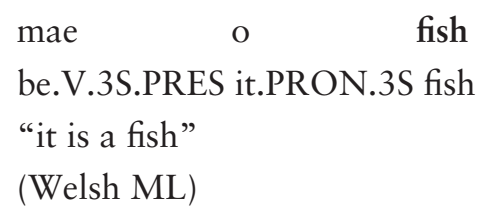

mae O fish

be.V.3S.PRES it.PRON.3S fish

"it is a fish"

(Welsh ML)
[Dewi20213 - Dewi]

Coding the ML was less straightforward for other utterances in our corpus. Because of the developmental nature of the data, verbal morphology was sometimes incomplete. For example, there is no verbal morphology available to analyse the ML of the utterances in Examples (15)-(16) by the SMP, 
nor does its word order differ from English in a way that would allow us to identify the ML by the MOP.

$$
\begin{array}{ll}
\text { mynd yn crash } \\
\text { go.V PRT } & \text { crash } \\
\text { "go crash" } &
\end{array}
$$

(16) catch yfana

[Dewi020126 - Dewi]

catch there

"catch(es) there"

In our analysis of utterances like the ones above, we chose to take the bare verb alone to indicate the ML of the utterance without insisting that the verb had to have finite marking and subject-verb agreement.

If an utterance did not have enough material to allow us to classify the ML according to either the MOP or the SMP, then we coded the ML as "Undetermined". This applied to Example (17). It is a mixed utterance, but there are no clues from the MOP because the order would be the same in English ("whoops-a-daisy again") and there's no verb, so we cannot classify the utterance using the SMP. $28.67 \%$ of all the mixed utterances included in our dataset had to be classified as Undetermined in this way.

$$
\begin{aligned}
& \text { woop a day eto } \\
& \text { whoops a daisy again } \\
& \text { "whoops-a-daisy again" }
\end{aligned}
$$

[Alaw200302 - Alaw]

\subsection{Method of Analysing the Adult Data in the CIG1 Corpus}

The CLAN programme was used to extract utterances that had been tagged by the original researcher as including English language material. If those utterances contained more than one clause, the mixed clause or clauses were identified and an ML assigned to each mixed clause. As with our analysis of the CIG1 child utterances, we applied the SMP and the MOP to determine the ML for the adult utterances. For example, the mixed clause in (18) was assigned Welsh as the ML. Following similar principles to those used in the child data, (19) is a unilingual clause which we excluded from the data set, and (20) was also excluded because the word helicopter could be either English or Welsh.

$$
\begin{aligned}
& \text { be mae hi 'n wneud yn kitchen? [Dewi011009- Dad] } \\
& \text { what be.V.3S.PRES she.PRON.F.3S PRT do.NONFIN in kitchen } \\
& \text { "what is she doing in the kitchen?" }
\end{aligned}
$$


(20) lle mae

helicopter

[Dewi0202172 - Sue]

where be.V.3S.PRES helicopter

"where is the helicopter?"

\section{Results}

\subsection{CIG1 Data Analysis (Child Speech)}

Figure 3.1 shows the ML distribution for all the child speakers across the corpus. Of all of the mixed utterances with determinable ML, $96.73 \%$ of the utterances had Welsh ML, while only $3.27 \%$ of the utterances had English ML. Figure 3.2 shows the distribution of ML for each individual speaker. All the mixed utterances with a determinable ML produced by Elin, Bethan, Melisa, and Rhian had a Welsh ML with no instances of English ML. This could be in part due to the smaller sample size for those four speakers. Elin had 11 utterances with a determinable ML, Bethan had 2, Melisa had 13, and Rhian had 10. Alaw, Dewi, and Rhys all had high levels of Welsh ML with $97.73 \%, 89.13 \%$, and $98.86 \%$ Welsh ML, respectively.

\subsection{Comparison with Siarad Data}

Figure 3.3 shows the distribution of the ML in the mixed utterances of the Siarad corpus (left-hand side) compared with the mixed clauses of the CIG1

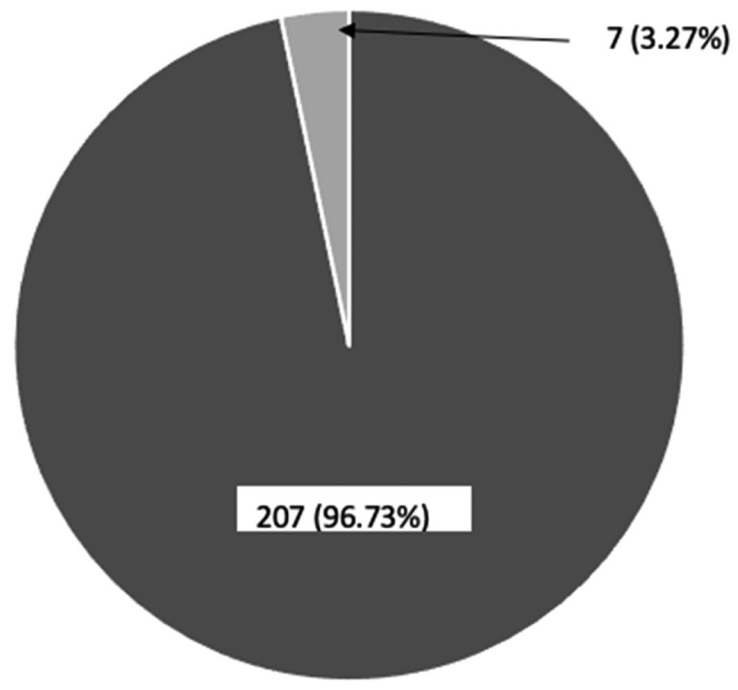

- Welsh ML $\quad$ English ML

Figure 3.1 Matrix language distribution in child mixed utterances 


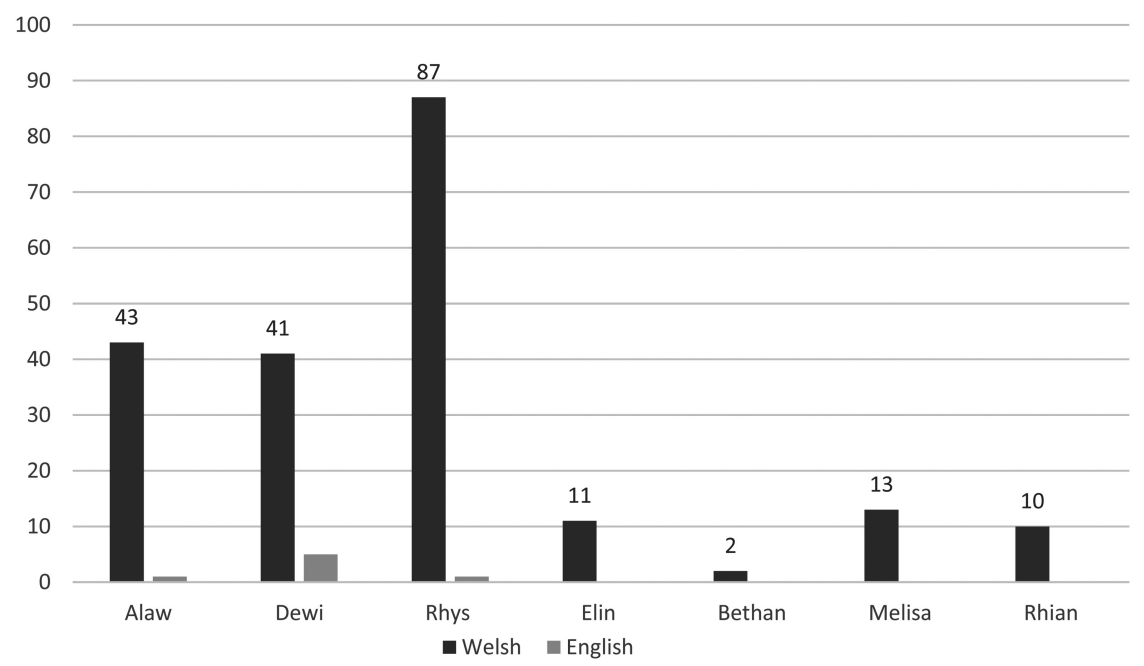

Figure 3.2 Matrix language distribution in individual child mixed utterances

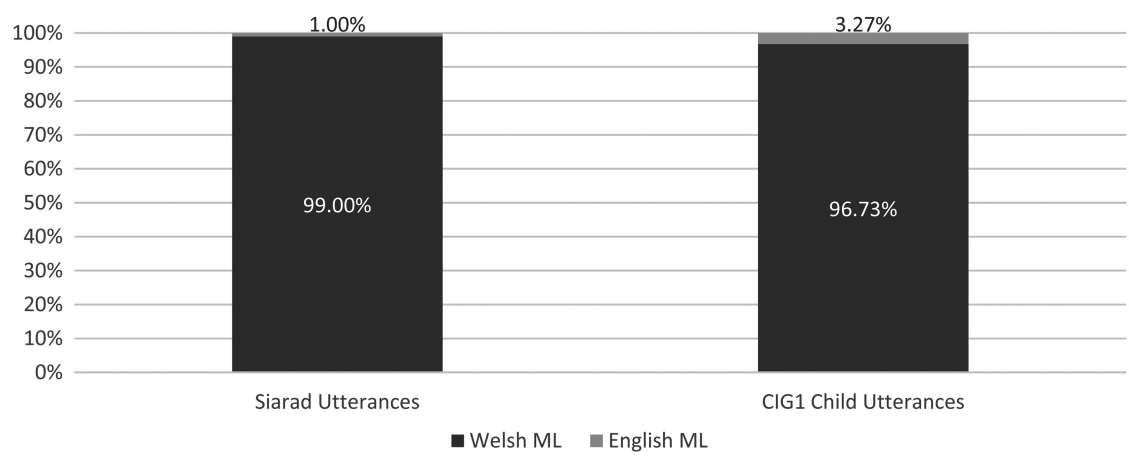

Figure 3.3 Matrix language distribution in Siarad adult corpus compared with child mixed utterances in CIG1

child corpus (right-hand side). In both figures cases of Undetermined ML are excluded. The Siarad data are based on Table 5.3 of Deuchar, WebbDavies, and Donnelly $(2018,90)$. There were 53 utterances with English ML and 5908 utterances with Welsh ML in the Siarad mixed data. There is a striking similarity between the ML distribution across the Siarad and the CIG1 corpora. For clauses with an assignable ML, 99\% had Welsh ML in Siarad and $96.73 \%$ had Welsh ML in the CIG1 child data.

\subsection{Comparison with Dewi Adult Data}

The results from the analysis of adult speech in the Dewi transcripts indicated a total of 126 mixed utterances with 108 Welsh ML, 1 English ML, 


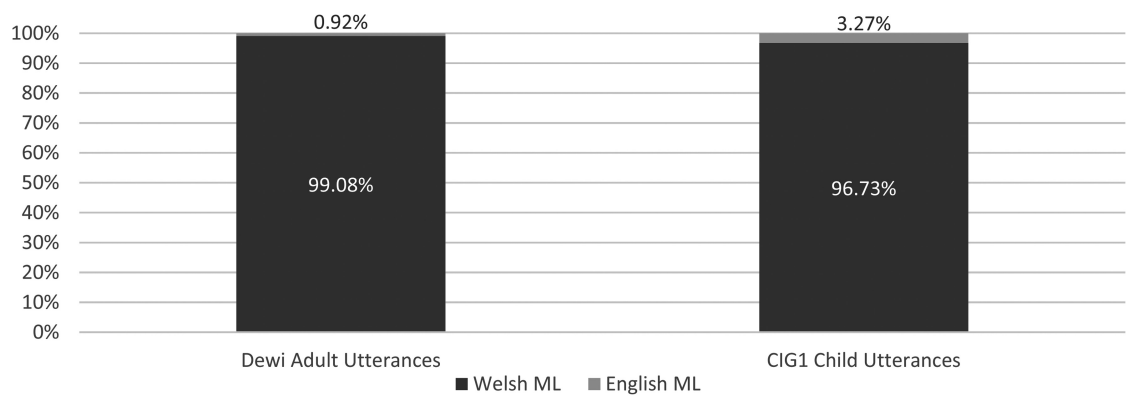

Figure 3.4 Matrix language distribution in mixed utterances by Dewi's adult interlocutors compared with child mixed utterances

and 17 Undetermined ML. There was a distribution of 99.08\% Welsh ML and $0.92 \%$ English ML (see Figure 3.4). Thus, in both the child CIG1 data and the adult data from the Dewi transcripts, Welsh is overwhelmingly the most frequent ML.

\subsection{Refining the Criteria: Child Mixed Utterances Containing Verbs}

One potential criticism which might be proposed of the methodology of analysis applied to the child data is that we took the language source of all verbs, whether inflected or not, as indicative of the SMP in identifying the Matrix Language of the utterance. So as outlined previously, the bare verb mynd "go" in Example (15) (repeated below) was taken to indicate Welsh subject-verb agreement because an equivalent adult utterance would have the verb as part of a periphrastic construction with a finite auxiliary verb.

$$
\begin{aligned}
& \text { mynd yn crash } \\
& \text { go.V PRT crash } \\
& \text { "go crash" }
\end{aligned}
$$

Example (21) provides an idea of how mynd might appear in an adult periphrastic construction with the auxiliary mae as the finite verb:

$$
\begin{aligned}
& \text { mae Postman Pat yn mynd i 'r gegin [Rhys020305-Sue] } \\
& \text { be.V.3S Postman Pat PRT go.NONFIN to the kitchen } \\
& \text { "Postman Pat goes to the kitchen" }
\end{aligned}
$$

However, we know from studies of Welsh language acquisition that such periphrastic constructions develop gradually in children and that they are preceded by shorter and simpler versions (see, e.g. Aldridge et al. 1998). Even in adult speech, the auxiliary is sometimes deleted, as studied in detail 


\section{Shannon Phillips and Margaret Deuchar}

by Davies and Deuchar (2014), so our use of bare verbs in Welsh to indicate the ML may be defensible. However, to ensure that this method did not unduly influence our results, we decided to conduct a second analysis of the child speech in which we allowed bare verbs to be considered equivalent to reduced periphrastic constructions only if the child had already shown evidence of producing full periphrastic constructions either in the same transcript as the occurrence of the bare verb or in one of an earlier recording.

For this second analysis we first isolated the mixed utterances with bare verbs but no finite marking as in Example (22).

$$
\begin{aligned}
& \text { wneud magic } \\
& \text { do.V magic } \\
& \text { "do magic" }
\end{aligned}
$$

[Rhys020027 - Rhys]

For these utterances, we introduced a criterion requiring that for a bare verb in a phrase to be considered equivalent to a reduced construction, there needed to be evidence of subject-verb agreement used by the child either within the same transcript or within a transcript recorded earlier in the child's development. If the child displayed earlier evidence of acquiring the full version of the proposed reduced construction, then we accepted the bare form as having a classifiable ML by the SMP.

For instance, in Example (23) there is no finite verb, only a bare verb mynd. This example was taken from transcript $020212 \mathrm{~b}$, recorded when Alaw was 2;2,12. However, in an earlier transcript 010119, recorded when Alaw was $1 ; 1,19$, she produced a full periphrastic construction (Example (24)), suggesting that she had already acquired the full construction. We therefore classified the utterance in (23) as having a Welsh ML based on the bare verb as we had done in our first analysis.

$$
\begin{aligned}
& \text { hwn yn mynd i crash rwan } \\
& \text { this PRT go.NONFIN to crash now } \\
& \text { "this is going to crash now" }
\end{aligned}
$$

$$
\begin{aligned}
& \text { mae car yn mynd i fana. [Alaw010119-Alaw] } \\
& \text { be.V.3S.PRES car PRT go.NONFIN to there } \\
& \text { "the car is going there" }
\end{aligned}
$$

Similarly, we applied this stricter criterion to the utterances with only bare verbs in English, requiring that children show evidence of the previous acquisition of forms with full subject-verb agreement. For instance, Example (25) contains a verb in English but has no overt subject-verb agreement. There was no evidence of the speaker Dewi producing any utterances with full subject-verb agreement in English in any of the earlier transcripts, so the 
utterance in (25), previously coded as English ML on the grounds that the verb was English, was now coded as Undetermined ML.

$$
\begin{aligned}
& \text { push na } \\
& \text { push not } \\
& \text { "no push" }
\end{aligned}
$$

[Dewi020227 - Dewi]

\subsubsection{Results}

Figure 3.5 below shows the results from the initial analysis in the left-hand column, which reports the same information as Figure 3.1 with $96.73 \%$ Welsh ML and 3.27\% English ML across the child mixed-language utterances in the corpus. The right-hand column shows the results of the second analysis applying a stricter criterion to utterances with bare verbs and no verbal morphology. For the second analysis there was an average of $98.50 \%$ Welsh ML and 1.50\% English ML. We can see from Figure 3.5 that the distribution of the ML in the two charts is very similar, suggesting that the application of the less strict criteria did not have a significant effect on the results.

\section{Discussion}

The principal question that this study sought to address was whether there was a similarity in the code-switching patterns of children and adults from the same speech community. The results presented here confirm that similarity. In the comparison of the CIG1 data with Deuchar, Webb-Davies, and Donnelly's (2018) analysis of Siarad, both samples showed an overwhelming majority of Welsh ML in mixed utterances. In other words, both the bilingual adults in the community and the developing bilingual children adopt similar code-switching patterns using their two languages, Welsh and English.

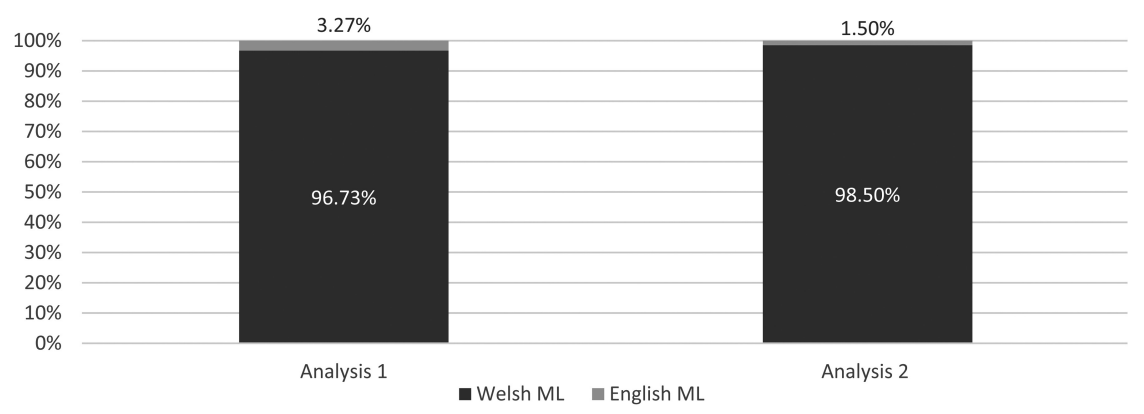

Figure 3.5 Matrix language distribution in child mixed utterances comparing Analysis 1 and Analysis 2 


\section{Shannon Phillips and Margaret Deuchar}

Our results show that the children adopt the same code-switching pattern as the adults, in which English words and phrases are inserted into a Welsh morphosyntactic frame in the overwhelming majority of their mixed utterances. The reverse pattern, which could theoretically occur, in which Welsh words or phrases might be inserted into an English morphosyntactic frame, is virtually absent.

The results of doing the same analysis on a small sample of the adults speaking on the CIG1 transcripts from the child speaker Dewi indicated a very similar pattern of results. These results show that the type of codeswitching input being received by the children in real time during the recordings had a Welsh syntactic frame the majority of the time. Because the Siarad corpus had a very similar pattern of ML distribution, we take these results as an indication that the Siarad corpus is a plausible proxy for the input to the child speakers in CIG1.

Overall, our results show that, even allowing for the developmental nature of child speech in such young children, their code-switching patterns reflect quite closely the speech of adults in the same bilingual community. This finding is supported by the fact that our small study of the speech specifically directed by adults to Dewi showed the same patterns. This close relationship between the ML in the adult input and in child speech has not to our knowledge been previously demonstrated. Referring back to previous work we therefore find support for Eichler, Hager, and Müller's (2012) finding regarding the crucial role of the ML in child code-switching patterns. However, we have gone one step further in tracing the choice of the ML to its frequency in the input, thus providing support for a usage-based approach to bilingual acquisition. In line with the results from Yip and Matthews (2016) and Eichler, Hager, and Müller (2012), the results here suggest that children are code-switching because they are acquiring the patterns of speech produced in the input available to them. There is a striking similarity found here between the children's ML distribution and the ML distribution in the input to them and this input is provided not only by their parents but also by other adults in the community.

Interestingly, these results indicate that the age at which the children start reproducing adult code-switching patterns is much earlier than 3 years old, contrary to previous findings by Nicoladis and Genesee (1997). The material used in our study came from transcripts when the children were between the ages of $1 ; 9$ and 2;6. More research into different code-switching contexts is of course necessary in order to determine whether this behaviour of reflecting adults' code-switching input patterns at such a young age is the norm or an exception.

This study only focuses on one language pair (Welsh/English), and only data from communication between bilinguals has been analysed. Furthermore, the pattern of ML usage in this community is not found in all adult bilingual communities. It would be informative to study the 
code-switching acquisition pattern of children in other bilingual communities, which show a different distribution of the ML. For instance, the analysis of the ML of Spanish/English data from Miami shows variation between English ML and Spanish ML in the code-switching of the adult population (Parafita Couto et al. 2014). It would be fruitful to test the prediction that child ML distribution will mirror adult ML distribution on the Miami data. Comparing input relationships in contact situations where the predominant ML of either the adults or the children is in the process of change would also be fruitful, especially because ML changes have previously been linked to language attrition (cf. Myers-Scotton 2002, 251).

One consequence of the focus mentioned above on communication between bilinguals is that we have not been able to study how children acquire the ability to code-switch between utterances as a result of a change in interlocutors. All Welsh speakers in Wales need to address monolingual English-speaking interlocutors on some occasions, and hence to switch from Welsh to English when the situation demands it. This did not arise in the data we analysed because all speakers were bilingual. However, Deuchar and Quay (2000) were able to show that an English/Spanish developing bilingual accommodated in her language choice to that of her interlocutor as young as $1 ; 7$. It would be interesting to investigate the development of this language accommodation ability in a study of Welsh/English bilingual children addressing English monolinguals.

\section{Conclusion}

The results from this investigation into Welsh/English child code-switching indicate that the adult input plays an important part in influencing the patterns of the children's code-switching. The ML distribution for the codeswitching of adult and child populations surveyed was strikingly similar. The results from our investigation of adult speakers in the community (as in the Siarad corpus) and speakers on the CIG1 corpus recordings both indicate the same pattern of switching as that found in the child speech. Furthermore, our validity check on the main analysis of child speech in our second analysis yielded the same results. The main contribution of this investigation is that it provides a new angle for further study into child code-switching research, specifically looking at the effect of the adult input patterns on child code-switching. Where the motivations for child codeswitching have previously been tied to developmental stages and to dominance, further support is found here for an approach that suggests that child code-switching does not differ qualitatively from adult code-switching, at least if the choice of the Matrix Language is taken as the main criterion as in our study. The available evidence thus suggests that code-switching patterns in the same way as adult code-switching, and children acquire the patterns needed to code-switch with adult-like competence. 


\section{Appendix I}

\section{Gloss abbreviations}

$\begin{array}{ll}\text { 1S } & \text { 1st person singular } \\ \text { 3P } & \text { 3rd person plural } \\ \text { 3S } & \text { 3rd person singular } \\ \text { ADJ } & \text { adjective } \\ \text { ASP } & \text { aspect marker } \\ \text { CL } & \text { classifier } \\ \text { DEM } & \text { demonstrative } \\ \text { F } & \text { feminine } \\ \text { FUT } & \text { future/habitual present } \\ \text { M } & \text { masculine } \\ \text { NONFIN } & \text { non-finite verb } \\ \text { PL } & \text { plural } \\ \text { POSS } & \text { possessive } \\ \text { PREP } & \text { preposition } \\ \text { PRES } & \text { present } \\ \text { PRON } & \text { pronoun } \\ \text { PRT } & \text { particle } \\ \text { SFP } & \text { sentence final particle } \\ \text { SG } & \text { singular }\end{array}$

\section{Notes}

1 We use the terms "code-switching" and code or "language-mixing" interchangeably.

2 Information listed on the TalkBank website (https://childes.talkbank.org/access/ Celtic/Welsh/CIG1.html)

3 Many words coded as either Welsh or English are borrowings from English into Welsh. For further details of the transcription and language marking system see Deuchar, Webb-Davies, and Donnelly $(2018,35-42)$; and for our view on distinguishing code-switches from borrowings see Stammers and Deuchar (2012) and Deuchar, Webb-Davies, and Donnelly (2018) chapter 4.

4 Our data can be accessed at https://osf.io/gtj6v/

5 Bolded text indicates English language material. Underlined words in examples indicate material which could be Welsh or English.

6 Translations and glosses were added by the authors of the current paper.

7 We used the online version of Geiriadur Prifysgol Cymru see http://www.geiriadur.ac.uk/

8 For information regarding the transcribers' conventions for indicating uncertainty, see https://childes.talkbank.org/access/Celtic/Welsh/CIG1.html

9 The total refers to tokens rather than types; repeated utterances are included in the count.

\section{References}

Aldridge, M, R. Borsely, S. Clack, and G. Creunant. 1998. "The Acquisition of Noun Phrases in Welsh". In Language Acquisition: Knowledge Representation and Processing, edited by Antonella Sorace, Caroline B. Heycock, and Richard Shillcock. Edinburgh: University of Edinburgh Press. 
Baker, A. and B. van den Bogaerde. 2008. "Code-mixing in Signs and Words in Input to and Output from Children”. In Sign in Bilingualism: Language Development, Interaction, and Maintenance in Sign Language Contact Situations, edited by Carolina Plaza-Pust and Esperanza Morales-López, 1-28. Amsterdam: John Benjamins Publishing. doi:10.1075/sibil.38.04bak

Behrens, H. 2012. "Corpus Analysis of Child Language". In The Encyclopedia of Applied Linguistics, edited by C.A. Chapelle. Hoboken, NJ: Wiley. Doi:10.1002/9781405198431.wbeal0242

Blokzijl, J., M. Deuchar, and C. Parafita Couto. 2017. "Determiner Asymmetry in Mixed Nominal Constructions: The Role of Grammatical Factors in Data from Miami and Nicaragua". Languages 2 (4): 20. Doi:10.3390/languages2040020

Carter, D., M. Deuchar, P. Davies, and M.C. Parafita Couto. 2011. "A Systematic Comparison of Factors Affecting the Choice of Matrix Language in Three Bilingual Communities”. Journal of Language Contact 4: 1-31. Doi:10.1163/18 7740911X592808

Chomsky, N. 1980. Rules and Representations. Oxford: Blackwell.

Chomsky, N. 1986. Knowledge of Language: Its Nature, Origin and Use. New York; London: Praeger.

Comeau, L., F. Genesee, and L. Lapaquette. 2003. “The Modeling Hypothesis and Child Bilingual Codemixing”. International Journal of Bilingualism 2 (7): 113126. Doi:10.1177/13670069030070020101

Davies, P. and M. Deuchar. 2014. "Auxiliary Deletion in the Informal Speech of Welsh-English Bilinguals: A Change in Progress”. Lingua 143: 224-241. Doi:10.1016/j.lingua.2014.02.007

De Houwer, A. 1990. The Acquisition of Two Languages from Birth: A Case Study. Cambridge: Cambridge University Press.

Deuchar, M. 1999. “Are Function Words Non-Language-Specific in Early Bilingual Two-Word Utterances?” Bilingualism: Language and Cognition 2 (1): 23-34. Doi:10.1017/S1366728999000127

Deuchar, M. 2012. “Code-switching”. In The Encyclopedia of Applied Linguistics, edited by C. A. Chapelle, 675-664. New York: Wiley.

Deuchar, M. and A. Clark. 1996. "Early Bilingual Acquisition of the Voicing Contrast in English and Spanish". Journal of Phonetics 24 (3): 351-365. Doi:10.1006/jpho.1996.0019

Deuchar, M. and S. Quay. 2000. Bilingual Acquisition: Theoretical Implications of a Case Study. Oxford: OUP.

Deuchar, M. and M. Vihman. 2002. "Language Contact in Early Bilinguals". In Contact-Induced Language Change, edited by M.C. Jones and E. Esch, 267-281. The Hague: Mouton. Doi:10.1515/9783110892598.267

Deuchar, M. and M. Vihman. 2005. "A Radical Approach to Early Mixed Utterances”. International Journal of Bilingualism 9 (2): 137-157. Doi:10.117 7/13670069050090020201

Deuchar, M., P. Webb-Davies, and K. Donnelly. 2018. Building and Using the Siarad Corpus: Bilingual Conversations in Welsh and English. Vol. 18 of Studies in Corpus Linguistics. Amsterdam/Philadelphia: John Benjamins Publishing Company.

Döpke, S. 1992. One Parent, One Language: An Interactional Approach. Amsterdam: John Benjamins.

Eichler, N., M. Hager, and N. Müller. 2012. "Code-Switching within Determiner Phrases in Bilingual Children: French, Italian, Spanish and German”. Zeitschrift Für Französische Sprache Und Literatur 122 (3): 227-258. 


\section{Shannon Phillips and Margaret Deuchar}

Gardner-Chloros, P. 2009. Code-Switching. Cambridge: Cambridge University Press.

Gathercole, V.M. and E. Thomas. 2009. "Bilingual First-Language Development: Dominant Language Takeover, Threatened Minority Language Take-Up". Bilingualism: Language and Cognition 12 (2): 312 -237. Doi:10.1017/S136672 8909004015

Goodz, N. 1989. "Parental Language Mixing in Bilingual Families". Infant Mental Health Journal 10: 25-43. Doi:10.1002/1097-0355(198921)10:1<25:: AID-IMHJ2280100104>3.0.CO;2-R

Grimstad, M.B., T. Lohndal, and T.A. Åfarli. 2014. "Language Mixing and Exoskeletal Theory: A Case Study of Word-Internal Mixing in American Norwegian”. Nordlyd 41 (2): 213-237. Doi:10.7557/12.3413

Grosjean, F. 1989. "Neurolinguists, Beware! The Bilingual is not Two Monolinguals in One Person". Brain and Language 36 (1): 3-15. Doi:10.10 16/0093-934X(89)90048-5

Hebblethwaite, B. 2010. “Adverb Code-Switching Among Miami’s Haitian CreoleEnglish Second Generation”. Bilingualism: Language and Cognition 13 (4): 409-428.

Hoffmann, C. 1985. "Language Acquisition in Two Trilingual Children”. Journal of Multilingual and Multicultural Development 6 (6): 479-495. Doi:10.1080/01 434632.1985.9994222

Ihemere, K. 2016. "In Support of the Matrix Language Frame Model: Evidence from Igbo-English Intrasentential Code-Switching”. Language Matters 47 (1): 105-127. Doi:10.1080/10228195.2015.1110194

Joshi, A. 1985. "Processing of Sentences with Intrasentential Code-Switching". In Natural Language Parsing: Psychological Computational, and Theoretical Perspectives, edited by D. Dowty, L. Karttunen, and A. Zwicky. Cambridge: Cambridge University Press.

Khan, A.A. and A. Khalid. 2018. "Pashto-English Codeswitching: Testing the Morphosyntactic Constraints of the MLF Model”. Lingua 201: 78-91. Doi: 10.1016/j.lingua.2017.09.002

Köppe, R. 1997. Sprachentrennung im frühen bilingualen Erstspracherwerb Französisch, Deutsch. Germany: Narr.

Lanza, E. 1997a. Language Mixing in Infant Bilingualism: A Sociolinguistic Perspective. United Kingdom: Clarendon Press.

Lanza, E. 1997b. "Language Contact in Bilingual Two-year-olds and Codeswitching: Language Encounters of a Different Kind?*” The International Journal of Bilingualism 1 (2): 135-162. Doi:10.1177/136700699700100203

Langacker, R. 1987. Foundations of Cognitive Grammar. 2 vols. California: Stanford University Press.

MacWhinney, B. 1991. The CHILDES Project: Tools for Analyzing Talk. United Kingdom: Lawrence Erlbaum.

Myers-Scotton, C. 1993. Duelling Languages: Grammatical Structure in CodeSwitching. $1^{\text {st }}$ edition. Oxford: Clarendon Press.

Myers-Scotton, C. 2002. Contact Linguistics: Bilingual Encounters and Grammatical Outcomes. Oxford: Oxford University Press.

Newport, E, H. Gleitman, and L. Gleitman. 1977. "Mother I'd Rather Do It Myself: Some Effects and Noneffects of Maternal Speech Style". In Talking to Children: Language Input and Acquisition, edited by C. Snow and C. Ferguson. Cambridge: Cambridge University Press. 
Nicoladis, E., and F. Genesee. 1997. "The Role of Parental Input and Language Dominance in Bilingual Children's Code-Mixing”. In BUCLD 21 Proceedings, 422-432. Somerville, MA: Cascadilla.

Paradis, J., E. Nicoladis, and F. Genesee. 2000. "Early Emergence of Structural Constraints on Code-Mixing: Evidence from French-English Bilingual Children". Bilingualism: Language and Cognition 3 (3): 245-261.

Parafita Couto, M.C., P. Davies, D. Carter, and M. Deuchar. 2014. "Uniformity and Variability in the Choice of Matrix Language: A Tale of Two Communities". In Unraveling Bilingualism: A Cross-Disciplinary Perspective, edited by E. Thomas and I. Mennen, 111-140. Bristol: Multilingual Matters.

Patuto, M., M. Hager, L. A. Gil, N. Eichler, V. Jansen, A. Schmeißer, and N. Müller. 2014. "Child-External and -Internal Factors in Bilingual Code-switching: Spanish, Italian, French and German”. In Language Contact Around the Globe. Proceedings of the LCTG3 Conference, edited by A. Koll-Stobbe and S. Knospe. Bern: Peter Lang.

Petersen, J. 1988. "Word-Internal Code-Switching Constraints in Bilingual Child's Grammar”. Linguistics 26: 479-493.

Pfaff, C. 1979. "Constraints on Language Mixing: Intrasentential Code-Switching and Borrowing in Spanish/English”. Language 55 (2): 291-318.

Poplack, S. 1980. "Sometimes I'll Start a Sentence in Spanish Y TERMINO EN ESPAÑO". Linguistics 18: 581-618. Doi:10.1515/ling.1980.18.7-8.581

Stammers, J., and M. Deuchar. 2012. "Testing the Nonce Borrowing Hypothesis: Counter-Evidence from English-Origin Verbs in Welsh”. Bilingualism: Language and Cognition 15 (3): 630-643. Doi:10.1017/S1366728911000381

Vihman, M. 1985. "Language Differentiation by the Bilingual Infant". Journal of Child Language 12: 297-324. Doi:10.1017/S0305000900006450

Vihman, M. 1998. "A Developmental Perspective on Codeswitching: Conversations between a Pair of Bilingual Siblings". International Journal of Bilingualism 2 (1): 45-84. Doi:10.1177/136700699800200103

Yip, V. and S. Matthews. 2016. "Code-Mixing and Mixed Verbs in CantoneseEnglish Bilingual Children: Input and Innovation”. Languages 1 (4): 1-14. doi:10.3390/languages1010004

Yip, V. 2013. "Language Acquisition”. In The Psycholinguistics of Bilingualism, edited by F.L. Grosjean, 134. Hoboken: John Wiley \& Sons. 
